\title{
Multi-scale Characterization of Oxidized Zirconium Alloys
}

\author{
Yan Dong ${ }^{1}$, Arthur T. Motta ${ }^{2}$ and Emmanuelle A. Marquis ${ }^{1}$ \\ 1. Department of Materials Science and Engineering, University of Michigan, Ann Arbor, MI 48109 \\ 2. Department of Nuclear Engineering, Pennsylvania State University, College Park, PA 16802
}

Waterside corrosion remains one of the major limiting factors for the use of Zirconium alloys as cladding materials in the event of severe fuel duty conditions [1]. In the presence of small variations in the type and content of solutes added, zirconium based alloys can exhibit huge differences in corrosion behaviors. As illustrated in Figure 1, pure $\mathrm{Zr}$ lost protectiveness right away, while $\mathrm{ZrFeCr}$ alloy, created by adding small amount of $\mathrm{Fe}$ and $\mathrm{Cr}$ to $\mathrm{Zr}$, showed protective behavior for the whole duration of the test (500 days). To understand how alloying elements impact the protective character of oxide phases and the onset of oxide breakaway, atom probe tomography (APT) was combined with scanning electron microscopy (SEM), focused ion beam (FIB) milling, and transmission electron microscopy (TEM) to study microstructures and alloying element distributions in oxidized pure $\mathrm{Zr}$ and $\mathrm{ZrFeCr}$ alloy. The $\mathrm{ZrFeCr}$ alloy contains 0.4 wt.\% Fe and 0.2 wt.\% $\mathrm{Cr}$ as measured by hot vacuum extraction. The pure $\mathrm{Zr}$ contains around 0.01 wt. $\%$ Fe impurity.

In the initial stages of oxidation, the oxide layers on pure $\mathrm{Zr}$ and $\mathrm{ZrFeCr}$ are about the same thickness (less than $1 \mathrm{um}$ ) with some variations in the oxide thickness from grain to grain (Figure 1(b), (c)). The variation of oxide thickness indicates different oxygen diffusion rate along different crystallographic directions. The orientation dependence of the $\mathrm{ZrO}_{2}$ oxide thickness for crystal bar $\mathrm{Zr}$ and $\mathrm{ZrFeCr}$ is evaluated by combining FIB cross sectional imaging for oxide thickness measurement and backscattered electron diffraction (EBSD) for orientation mapping. In crystal bar Zr, the oxide is thicker for metal grains with basal planes parallel to the oxide/metal interface, while the growth rate in $\mathrm{ZrFeCr}$ appears to be independent of orientation. After 55 days, the oxide/metal interface in $\mathrm{ZrFeCr}$ remains relatively flat, while significant oxide ingress has occurred along grain boundaries of pure $\mathrm{Zr}$ (Figure 1(d), (e)).

The sequence of oxide-containing phases observed at oxide/metal interfaces consists of the stable oxide $\mathrm{ZrO}_{2}$, the suboxide $\mathrm{ZrO}$, a saturated solution of constant oxygen content at about $30 \% \mathrm{O}\left(\mathrm{Zr}(\mathrm{O})_{\text {sat }}\right)$, and an undersaturated solid solution of $\mathrm{O}$ in $\mathrm{Zr}(\mathrm{Zr}(\mathrm{O}))$ (Figure 2). The oxide morphologies correlate to the oxide growth kinetics for the $\mathrm{ZrFeCr}$ alloy. In the initial stage of oxidation (7days), the $\mathrm{ZrO}$ phase is not continuous and small $\mathrm{ZrO}$ plates are present at the $\mathrm{ZrO}_{2} / \mathrm{Zr}_{2} \mathrm{O}$ interface (Figure 2(b)). With longer corrosion time, the $\mathrm{ZrO}$ plates grow to form a continuous layer (Figure 2(c), (d)).

Fe segregation was observed at metal grain boundaries in both pure $\mathrm{Zr}$ and $\mathrm{ZrFeCr}$ alloy. The segregation levels are comparable as suggested by the concentration profiles across the grain boundaries (Figure 3). The Fe distribution in the oxide phases on top of the metal grain boundaries was also examined. The grain boundaries with Fe segregation extending from metal into the oxide appear to be more susceptible to faster oxide advance compared to the grain boundaries where Fe segregation is interrupted. On the other hand, initial TEM analysis indicated stronger degree of preferential orientation of oxide grains formed in pure $\mathrm{Zr}$ compared to $\mathrm{ZrFeCr}$ alloy. Therefore, differences in oxide microstructures or chemistry, rather than grain boundary chemistry in the metal, are more likely to contribute to the faster oxidation along metal grain boundaries and oxide growth instabilities. 
References:

[1] C. Lemaignan and A. T. Motta, Mater. Sci. Technol., 10B (1994) p. 1.

[2] This work was supported by the DOE Office of Nuclear Energy's Nuclear Energy University Program and the College of Engineering at University Of Michigan.
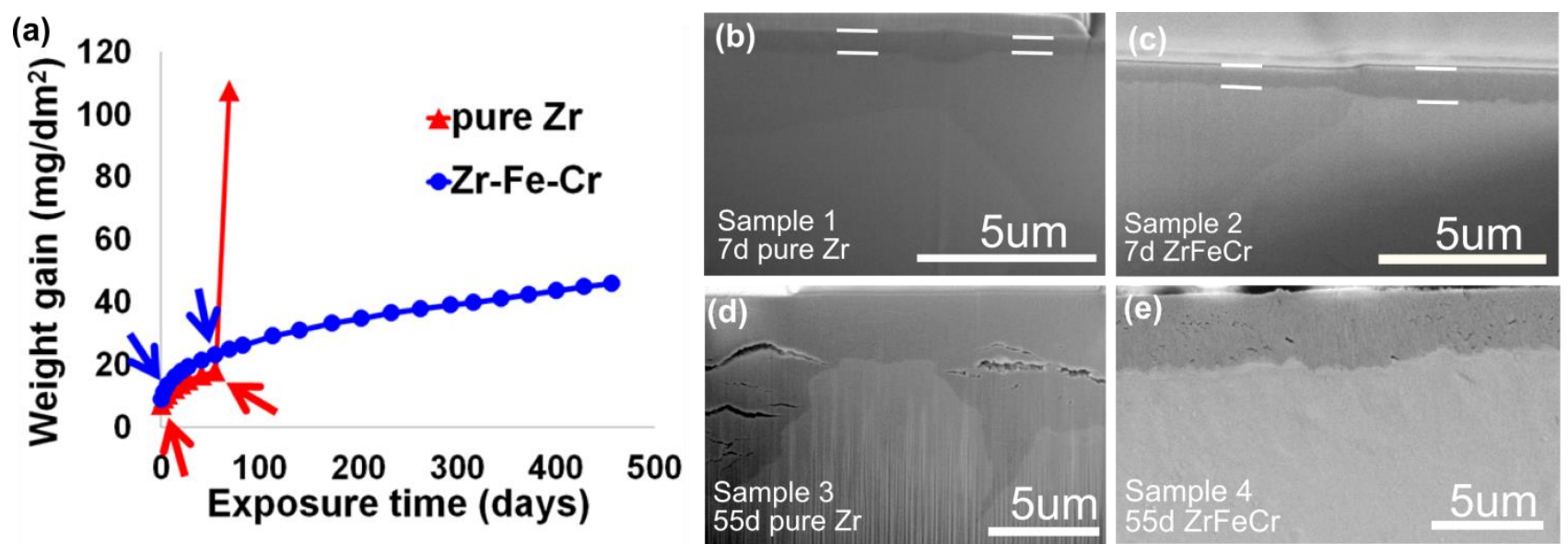

Figure 1. (a) Corrosion weight gain-exposure time curve for pure $\mathrm{Zr}$ and $\mathrm{Zr}$-Fe-Cr oxidized in $360^{\circ} \mathrm{C}$ water; (b)-(e) SEM images of the oxide/metal interfaces in pure $\mathrm{Zr}$ and $\mathrm{ZrFeCr}$ alloy that were oxidized for different amounts of time.
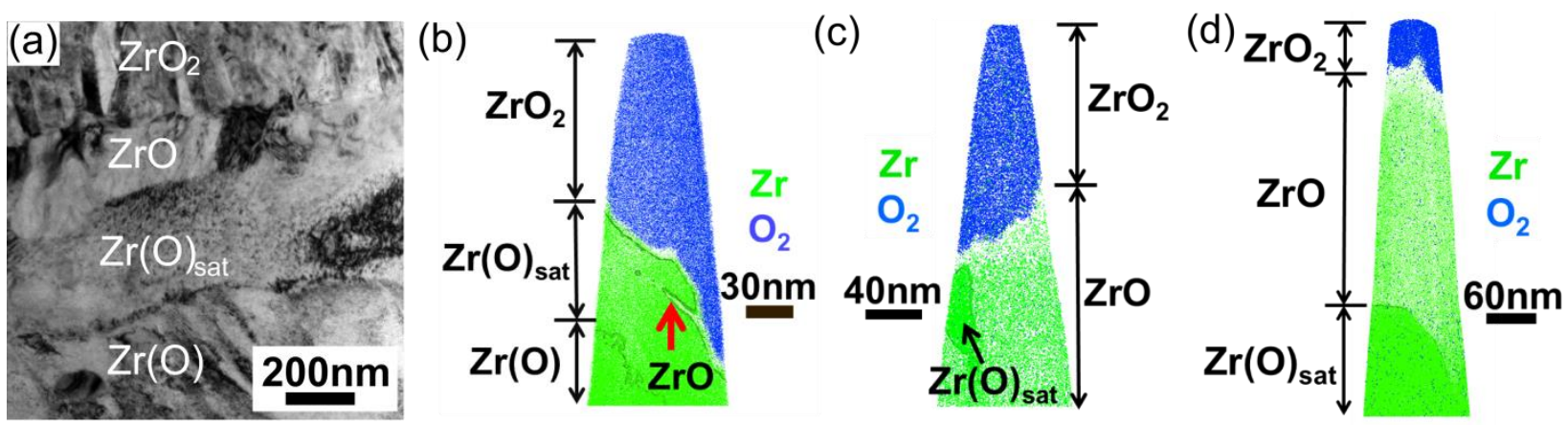

Figure 2. (a) TEM bright field image illustrating the four oxygen-containing phases observed at the metal/oxide interface (b)-(d): APT atomic maps from representative datasets obtained from the $\mathrm{ZrFeCr}$ alloy and showing the evolution of the ZrO phase after (b) 7 days, (c) 60 days, and (d) 456 days.
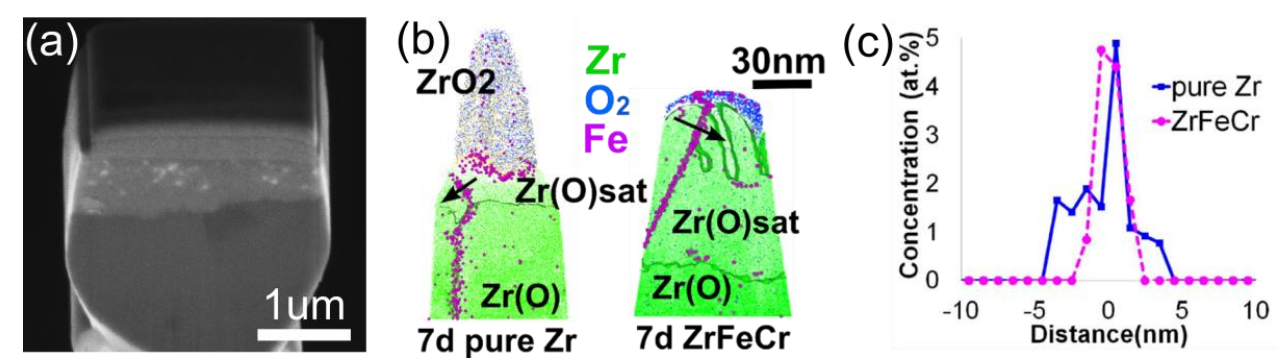

Figure 3. (a) SEM image of a non-sharpened APT tip that contains grain boundary; (b) Atomic maps of pure $\mathrm{Zr}$ and $\mathrm{ZrFeCr}$ alloy, both oxidized for 7 days; (c) Fe concentration profiles across grain boundary taken along the arrows shown in (b). 